\title{
Innovative approaches in the implementation of the Aquatic bioresources and aquaculture direction at Kuban state University
}

\author{
Alexey Abramchuk ${ }^{1, *}$, Mariya Kozub $^{1}$, Natalia Pashinova $^{1}$, Ksenia Abrosimova $^{1}$, and \\ Georgy Moskul ${ }^{1}$ \\ ${ }^{1}$ Kuban state University, 350040, 149 Stavropolskaya str., Krasnodar, Russia
}

\begin{abstract}
The Department of aquatic bioresources and aquaculture of Kuban state University trains students in the direction of 35.03.08 Aquatic bioresources and aquaculture (bachelor's degree), profiles Ichthyology and Aquaculture; 35.04.07 Aquatic bioresources and aquaculture (master's degree), orientation (profile) Ichthyology; 06.06.01 Biological Sciences (training of highly qualified personnel), profile 03.02.06 Ichthyology. An integral feature of a trained specialist, whose qualifications meet the current labor market conditions, is the acquisition of a set of research competencies in the field of fisheries science and production. The increasing inclusion of the research approach in the period of training, production practices and implementation of specialized disciplines, together with the educational approach, allows students to develop the necessary intellectual and creative thinking of students. Individual students with their works became winners and prize-winners in the all-Russian competition of the Final qualifying work's in the field of Aquatic bioresources and aquaculture.
\end{abstract}

\section{Introduction}

The Krasnodar territory is rich in water resources, which, taking into account the climatic conditions of the South of Russia, have a significant potential for the functioning of various categories of commercial aquaculture farms. They are represented by the AzovKuban estuaries, river reservoirs on steppe rivers, reservoirs, as well as lakes, ponds and other water bodies. In the second half of the XX century, the fishing industry of the region steadily occupied a leading position in the country, providing fish products in excess not only for its own needs, but also for neighboring regions. During this period, the fishing industry of the Krasnodar territory grew and sold about 26-35 thousand tons of pond fish, not counting fishing in the waters of the Black and Azov seas. Domestic political events of the early 1990s had a significant impact on the state of aquaculture production, its volumes fell sharply and by the middle of the decade were at the level of 6.5 thousand tons.the production crisis in the field of commercial fish farming was mainly due to a sharp increase

\footnotetext{
* Corresponding author: apilab@yandex.ru
} 
in the cost of feed, fertilizers, fish farming equipment and many other reasons. In addition to economic reasons, the issue of insufficient provision of fish farms in the region with qualified personnel (fish breeders and ichthyologists) has become acute. This happened against the background of a significant outflow of competent specialists to commercial structures and other sectors of the national economy. The lack of training areas for fisheries specialists (fish breeders) in the region's higher education Institutions worsened the situation every year. In 1997 by Order of the Minister of education and science (No. 872 of 12.05.1997), the specialty «Aquatic bioresources and aquaculture» was opened at the faculty of biology of Kuban state University. This decision of the rector of the University was preceded by numerous appeals from the heads of fishing enterprises in the South of Russia, which indicated the demand for ichthyologists-fish breeders in our region [1]. In 2003, 21 people received their first graduation and a diploma of higher education with the qualification «Ichthyologist-fish breeder» in the specialty Aquatic bioresources and aquaculture. Most of them remained true to their profession and continue to work in the fishing industry in their specialty. Since the opening of the specialty in the direction of "Aquatic bioresources and aquaculture», more than 260 graduates have received a diploma of higher education, the main part of which has filled the personnel deficit in the fishing industry of the region and neighboring regions.

\section{Discussion}

With Russia's entry into the Bologna process in 2003, the reform of the education system was aimed at increasing the mobility of citizens and reducing obstacles to free movement within the borders of the participating countries. In this regard, our country has introduced a two-level training system [2-4]. In accordance with national legislation, the system of higher education is being combined with postgraduate training, and the third level of higher education is being allocated - training of highly qualified personnel.

Currently, the higher education system of the Russian Federation includes three levels: bachelor's degree, specialty, master's degree, and training of highly qualified personnel. Each of these levels is implemented in accordance with a separate Federal educational standard of higher education (FES HE) and professional standards.

The Department of aquatic bioresources and aquaculture of Kuban state University trains students in the direction of 35.03.08 Aquatic bioresources and aquaculture (bachelor's degree), profiles Ichthyology and Aquaculture; 35.04.07 Aquatic bioresources and aquaculture (master's degree), orientation (profile) Ichthyology; 06.06.01 Biological Sciences (training of highly qualified personnel), profile 03.02.06 Ichthyology.

A bachelor's degree is a completed higher education. Upon completion of the program, the student is awarded the first academic qualification - a bachelor's degree in Aquatic bioresources and aquaculture. This diploma allows the graduate to fill a position for which the qualification requirements provide for higher education. They also have the opportunity to continue to improve their professional level by enrolling in a master's program in their profile, or choose a different direction of training.

Master's degree is the second stage of higher education, following the bachelor's degree, which allows you to deepen your specialization in a particular direction. A key aspect of training students in the master's program is research activities in the chosen field.

Training of highly qualified scientific and pedagogical personnel in postgraduate (adjunct) studies provides students with an appropriate level of education, during which it is mandatory to prepare a dissertation for the degree of candidate of Sciences.

Regardless of the level of education, one of the key tasks facing the teaching staff of the Department of aquatic bioresources and aquaculture is to adapt the content of educational programs taking into account scientific and technological progress in the fisheries industry. 
The implementation of this approach makes it possible to bring students as close as possible to the processes that occur in real time at enterprises and institutions and to develop their ability to adapt to the dynamic modern world.

An integral feature of a trained specialist, whose qualifications meet the current labor market conditions, is the acquisition of a set of research competencies in the field of fisheries science and production. The increasing inclusion of the research approach in the period of training, production practices and implementation of specialized disciplines, together with the educational approach, allows students to develop the necessary intellectual and creative thinking of students [14]. The development of these abilities is extremely important for the successful solution of current scientific and innovative problems in the field of fisheries. On the basis of the ichthyological laboratory and the laboratory of advanced technologies in aquaculture, which includes closed water supply installations and an aquarium complex, students study and implement their own projects under the guidance of mentors. The work constructed in this way contributes to the development of critical thinking, creative and creative abilities. Working in small groups on a specific scientific or industrial task is one of the ways that allow you to achieve the desired result in training specialists. The design method allows the student not only to study a specific topic in depth and in detail, but mainly to work out the algorithm for obtaining constantly updated information independently, without the direct participation of the teacher. Based on the results of individual stages and at the end of projects and experiments, a General review of the results is conducted (seminar-discussion, problem lecture, brainstorming). The method of discussion increases students ' motivation and involvement in the cognitive process, contributes to the formation and development of the ability to make independent judgments and defend their point of view, as well as teaches them to analyze and evaluate the views of others.

Students acquire the first basics of research work in the framework of abstract work and analysis of special literature, preparing their conclusions on the problem topics formulated by the teacher. Research work takes on a more complex form during the implementation of individual course projects. The curriculum for training bachelors in the direction of 35.03.08 Aquatic bioresources and aquaculture at Kuban state University provides for course projects in a number of disciplines: «Biological bases of fish farming», «Methods of fisheries research» and «Commercial fish farming». Implementation of the course project allows you to consolidate and apply the knowledge gained during the development of the discipline in solving specific production tasks. Students take the results of their own research and experiments as the basis for writing their qualification papers. Individual students with their works became winners and prize-winners in the all-Russian competition of the Final qualifying work's in the field of Aquatic bioresources and aquaculture: «Biological characteristics of the spawning herd of the Azov puzanok (Alosa caspia tanaica) in the Kuban river basin» (Shumeyko D. V.); "Growth rate of rainbow trout on various compound feeds» (Uvarova M. V.); «Species composition, distribution and main biological characteristics of fish-invaders in the internal reservoirs of the North-West Caucasus» (Polin A. A.); «Some features of the biology of river perch (Perca fluviatilis Linnaeus, 1758), living in the upper part of the Krasnodar reservoir» (Ismailov A. E.), etc.

The educational process in the modern world is characterized by large-scale signs of the digital revolution and a new technological order in industry. Digitalization of higher education means the transformation of the educational and management process due to the introduction of technologies for creating, processing, exchanging and transmitting large amounts of information on non-paper media $[5,6]$.

The development of digital technologies in higher education is characterized by a significant number of positive aspects, including providing students with access to educational and professional information resources, helping to build and implement 
individual educational trajectories, and optimizing interaction between teachers and students. This approach is aimed at activating students ' interest in learning, increasing their involvement in the educational process, and as a result — improving the quality component of professional training of graduates [7-9]. At the same time, it is important to understand that the introduction of such technologies should not change the comprehensive training model, since training of specialists in the field of Aquatic bioresources and aquaculture is not possible only in the form of online courses, they can be considered as additional training opportunities. Desk processing of the material, laboratory and practical work should be carried out only in full-time and direct pedagogical contact.

The reality of the modern world is characterized by an avalanche of knowledge development and information dissemination, as well as information clogging. These dynamic processes must necessarily be reflected in the educational process and the education system. Every year we see the steady and irreversible introduction of a whole range of digital devices, including mobile devices, capable of generating, storing and transmitting a significant amount of information to all age groups of the population. Against this background, there is a change in the process of perception of the surrounding world, in which the visual image exceeds the printed or oral one. In this regard, it is important not only to fully provide the proposed material with visual elements, but also to develop the imagination and creative thinking of the student.

The most important part of bachelor's and master's training in the field of Water bioresources and aquaculture is environmental education, which is a reflection of the sociocultural relations of the individual with the surrounding nature and people. This attitude is entirely based on the intellectual and spiritual spheres of the individual. The result of environmental education is the ecological culture of the individual [10-13]. The Department of aquatic bioresources and aquaculture implements a comprehensive approach to the formation of an ecological worldview and the development of knowledge and skills of students in the field of protection and rational use of the surrounding world (Fig. 1). 


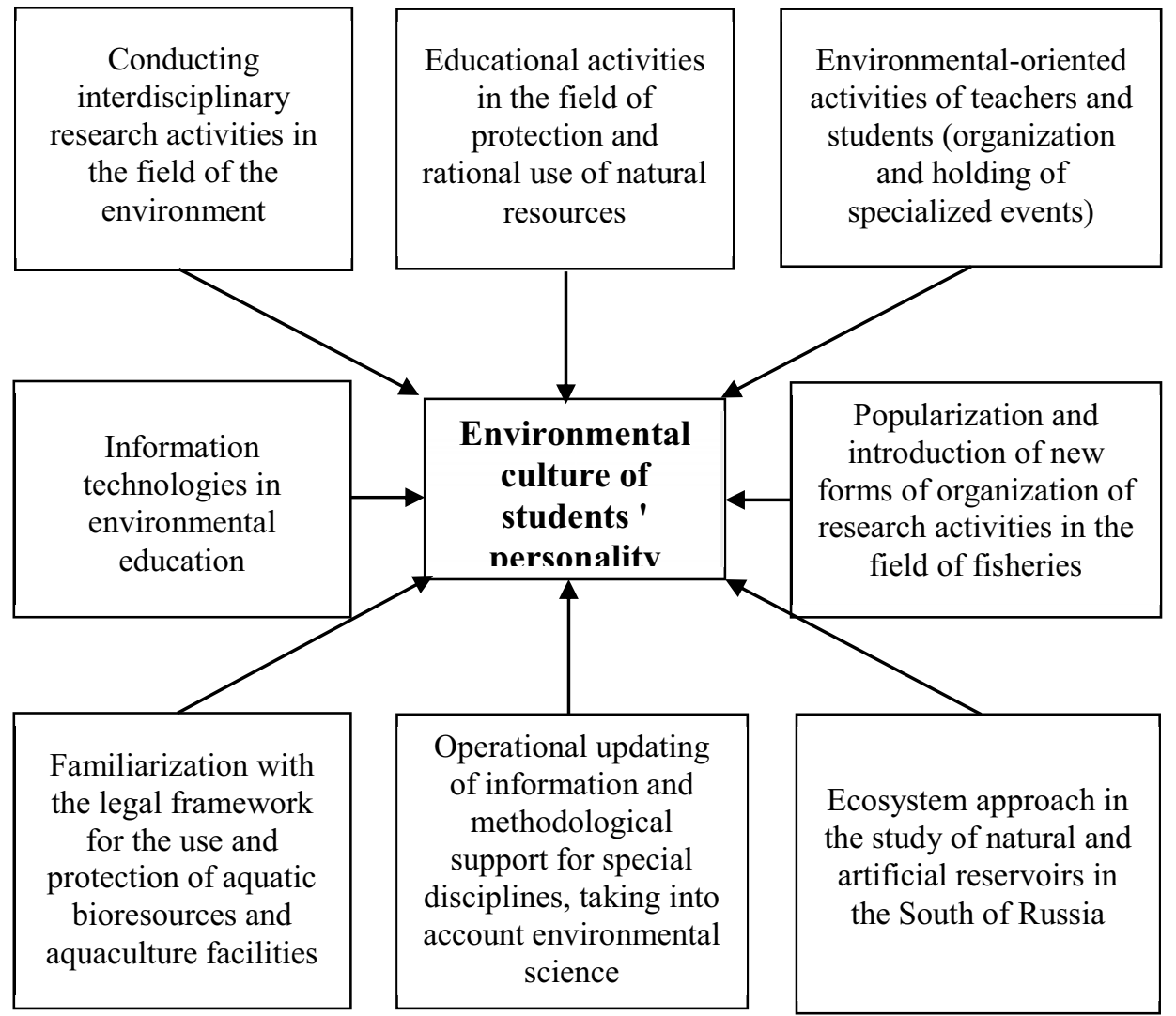

Fig. 1. Scheme of formation of ecological culture of the student's personality

For the purpose of mutual exchange of information and activation of students ' interest, interdisciplinary research events (conferences, round tables, seminars, etc.) on ecology and protection of water ecosystems in the southern regions of Russia are implemented together with students of other faculties and training areas (ecology, hydrology, hydrochemistry).

It is extremely important to involve students in educational and career-oriented activities in the field of protection and rational use of aquatic biological resources and their habitat at different levels of education (General (primary, basic, secondary), secondary vocational education, higher education), since in this case the worldview of young people is strengthened in an accessible one-level language of their peers [14-15].

The main task of ensuring high quality of professional training and demand for graduates is realized by integrating the fundamental theoretical training of students with the practical part, which becomes possible due to the involvement of students in the process of conducting applied scientific and industrial work.

One of the characteristic features of the implementation of educational activities in the field of Aquatic bioresources and aquaculture is a fundamental practical orientation, which increases the importance of industrial practices and internships. This approach is noted in the work of many Russian Universities.

Thanks to the long-term and fruitful cooperation of the Department of aquatic bioresources and aquaculture with specialized organizations and institutions, students and postgraduates of Kuban state University have the opportunity to participate in the implementation of fundamental and applied projects. Such cooperation allows graduates to fully master the technological processes at fish hatcheries, hone the methods of 
ichthyological and fisheries research in scientific institutions, join the activities of environmental structures, and return to the industry as ready-made specialists at the end of their training. As the basis of Praktik, I use both structural divisions of the University (Novorossiysk educational and research marine biological center, laboratory of advanced technologies in aquaculture of the KubSU Business incubator), and specialized institutions and organizations, and, first of all: GKU KK «Kubanbioresursy», FGBUN «Institute of marine biological research named after A. O. Kovalevsky RAS», FGBNU «All-Russian research Institute of freshwater fisheries», FGBNU «Southern scientific center of RAS», southern branch FGBUN «Institute of Oceanology named after P. P. Shirshov", FGUP «Breeding trout plant "Adler"», FSUE «The Adler industrial experimental salmon fishbreeding plant», JSC «Spetsrybzavod», plants of the Azov-Black sea branch of FSBE «Glavrybvod» and many others.

Professional skills and abilities of future employees of the fisheries industry are largely formed not only in the University, but also in the production environment of enterprises, in the course of work under the guidance of expert practitioners who use and implement the world experience of ichthyological research and aquaculture. Together with specialists, trainees gain significant experience in obtaining offspring in vivo, incubating eggs and growing sturgeon larvae, as well as an environmentally sound method for replenishing natural fish populations listed in the Red books of the Russian Federation and the Krasnodar territory.

The subjects of students ' final qualifying works are very diverse, demonstrating both an ecological approach to conducting research and ichthyological work, as well as solving issues of artificial reproduction of hydrobionts and commercial aquaculture.

\section{Conclusions}

Graduates of the Department of aquatic bioresources and aquaculture of Kuban state University have a high level of professional training and have the potential to successfully work in the scientific field, fisheries enterprises and environmental organizations.

\section{References}

1. A. V. Abramchuk, N. G. Pashinova, G. A. Moskul, Training of fisheries personnel at the Kuban state University. Materials of scientific events dedicated to the 15th anniversary of the southern scientific center, Russian Academy of Sciences: International scientific conference "Achievements of academic science in the South of Russia"; International youth scientific conference "Oceanography in the XXI century: current facts, models, methods and tools" to the memory of corresponding member RAS D. G. Matishov; all-Russian scientific conference "Aquaculture: international experience and Russian developments", 525-526 (Rostov-on-Don, YuNTS RAS, 2017)

2. D. Rich, International Encyclopedia of Education (Third Edition), 566-572 (2010) doi:10.1016/B978-0-08-044894-7.00848-4

3. T. I. Avdeeva, A. D. Kulik, L. A. Kosareva, T. A. Zhilkina, A. Y. Belogurov, European Research Studies Journal, 20, 112-124 (2017)

4. L. Safiullin, A. Fatkhiev, L. Safiullina, A. Shigabieva, Procedia - Social and Behavioral Sciences, 191, 1124-1127 (2015) doi:10.1016/j.sbspro.2015.04.605

5. H. Santos, J. Batista, R. P. Marquesa, Procedia Computer Science, 164, 123-130 (2019) doi: 10.1016/j.procs.2019.12.163 
6. N. C. Jackson, Business Horizons, 62, 761-772 doi:10.1016/j.bushor.2019.08.002

7. H. Hamidi, M. Jahanshaheefard, Telematics and Informatics, 38, 207-224 (2019) doi:10.1016/j.tele.2018.10.002

8. K. Md. Saifuddin, P. J. Lykkegaard, Procedia - Social and Behavioral Sciences, 228, 614-621 (2016) doi:10.1016/j.sbspro.2016.07.094

9. H. Crompton, M. Bernacki, J. AGreene, Current Opinion in Psychology, 36, 101-105 (2020) doi:doi.org/10.1016/j.copsyc.2020.04.011

10. N. M. Mingazova, Procedia - Social and Behavioral Sciences, 131, 85-89 (2014) doi:10.1016/j.sbspro.2014.04.083

11. E. N. Manolisa, E. N. Manolib, Journal of Cleaner Production, 279, 123614 (2020) doi:10.1016/j.jclepro.2020.123614

12. F. Fatkullina, E. Morozkina, A. Suleimanova, Procedia - Social and Behavioral Sciences, 214, 571-577 (2015) doi:10.1016/j.sbspro.2015.11.762

13. N. M. Ardoin, A. W.Bowersd, E. Gaillarde, Environmental education outcomes for conservation: A systematic review, Biological Conservation, 241, 108224 (2020) doi:10.1016/j.biocon.2019.108224

14. A. V. Abramchuk, M. A. Kozub, The role of environmental education in the preparation of students of the direction 35.03 .08 Aquatic bioresources and aquaculture. Aquatic bioresources and aquaculture of the South of Russia: materials of the all-Russian scientific and practical conference dedicated to the 20th anniversary of the opening of the training course "Aquatic bioresources and aquaculture", 8-9, Krasnodar, Kuban state University (2018)

15. E. B. Ali, V. P. Anufriev, Helyon, 6, e04719 (2020) doi:10.1016/j.heliyon.2020.e04719 